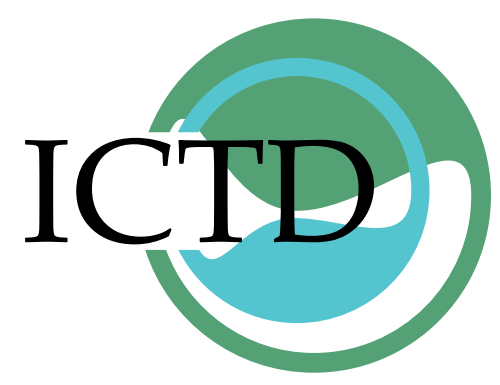

\title{
Environmental Taxation and Development
}

This paper reviews the potential of environmental taxation to address dual objectives of tackling a range of environmental pressures in developing countries, while at the same time increasing tax revenue. Other objectives including poverty reduction and economic growth are also considered.

\section{Forms of environmental taxation}

An environmental tax is one whose tax base is a physical unit (or a proxy of it) that has a proven, specific negative impact on the environment. The paper discusses different forms of environmental taxation (and subsidies) relevant to different kinds of activity, which have different implications for how best to seek alignment of private and social benefits. For example, taxes that directly target air and waterborne pollutants can be effective in providing incentives for firms to find more cost-effective ways of reducing effluents. However such taxes remain relatively rare, although China is planning to increase currently low tax rates for water and air pollution. Taxing renewable natural resources such as forests requires policymakers to balance revenue and production goals with the benefits that forests offer local people, as well as global benefits arising from their function as carbon sinks and conservers of biodiversity. The advent of external payments under REDD+ is a complicating factor, and these need to be aligned with domestic systems of taxation and regulation. Taxing natural resources poses particular problems for governments in terms of choosing what rates to apply to ensure sufficient revenue is captured (auctioning extraction rights could prove effective, if properly managed). There are also problems of enforcing rules (for example to control illegal logging or overfishing), and of limiting corruption; and taxation may not be very effective in fostering sustainable resource management. Greater involvement of forestbased communities could offer a way forward, as well as complementary policies (for example establishment of local production facilities to provide incentives for sustainable management of fisheries, as has been done in Namibia). In other cases more indirect taxes - for example on petrol or fossil fuels - can be effective in reducing emissions and can be relatively easy to administer and monitor.

\section{Impact of environmental taxation}

The paper examines evidence about the impact of environmental taxation on developing countries. There may be potential for environmental taxation to achieve other goals as well, for example increasing revenue or > 
addressing poverty and growth. But this is not straightforward. Environmental taxes are only likely to generate meaningful levels of revenue under certain conditions, for example if the goods in question are relatively price inelastic. Moreover environmental goals are more likely to be achieved when tax revenue is used to support environmental aims (for example research into clean alternatives).

Environmental taxes can be regressive, depending on the incidence of the tax and how revenue is used. Measures to reduce the negative impact on poor people can also reduce the environmental impact of taxation, as well as reducing tax revenues. Evidence about the ability of environmental taxes to generate growth is mixed, and largely theoretical. Achieving more than one goal from environmental taxation is challenging, and achieving "triple dividends" (for example revenue gains and poverty reduction as well as environmental benefits) is even harder.

\section{Success factors}

Experience from both developed and developing countries suggests that environmental taxation is most likely to succeed when it is carefully designed to reflect local goals and circumstances, and has political support. More specifically, when the primary goal is environmental, it is important that taxation should not compromise other policy goals - for example preserving economic competitiveness. Public support needs to be built and maintained, paying attention to equity issues; and complementary policies (for example targeted subsidies, or revenue hypothecation) can increase effectiveness. When the primary goal is to increase revenue, it is especially important to pay attention to the price elasticity of the goods in question. It is also important to set appropriate and dynamic rates, and to avoid taxation where enforcement costs are excessively high. Pursuing multiple goals is likely to be difficult and can compromise effectiveness of primary objectives.

\section{A decision-making framework for policymakers}

When weighing the merits of environmental taxation it is important to consider:

- What the policy goals should be, in relation to the importance of the issue for the country concerned; and whether the primary goal is environmental or some other aspect of policy.

-Who would benefit from the proposed measures and who should bear the costs? For example are benefits mainly local, national, regional or global?

-What inputs are most likely to deliver the goals? Are the appropriate tools economic instruments, regulation or taxation? Administrative capacity is an important consideration.

- If taxes are appropriate, how should they be structured to influence behaviour? Should they be levied directly on outputs (for example air or water pollution) or more indirectly on inputs (for example fuel)?

- How can support be maintained? Environmental taxes are designed to be noticeable, and are therefore unpopular. Resistance is likely to increase if such taxes are perceived as being really revenue-raising devices, and inequitable. Being transparent and linking revenues directly to popular policy goals may help reduce opposition.

\section{Research gaps}

There is a need for more empirical research on both technical and political economy aspects of environmental taxation to understand its potential and its limitations. Priorities include exploring the impact of REDD+ and other global mechanisms on domestic environmental policy including taxation. It is also important to understand better the processes through which environmental tax reforms emerge, to track their impact and explore the determinants of effectiveness. The economics and political economy of fuel subsidies are also a high priority.

\section{Further reading}

Spratt, S. (2012)

Environmental Taxation and Development: A Scoping Study ICTD Working Paper 2, Brighton: IDS, June

\section{Credits}

This ICTD Research In Brief was written by Stephen Spratt, Research Fellow in the Globalisation Team at IDS. His research interests relate to development finance, capital flows and investment, financial regulation, climate change finance, environmental taxation, low carbon development and the intersection between these issues. Summary by Sue Unsworth, Principal with The Policy Practice and a former Chief Governance adviser at DFID.

This brief was produced by the International Centre for Tax and Development (ICTD), a global policy research network which aims to generate and disseminate relevant knowledge to policymakers and mobilise knowledge in ways that will widen and deepen public debate about taxation issues within poorer countries. It is supported with UK aid from the UK government and by the Norwegian Ministry of Foreign Affairs (MFA).

The opinions expressed are those of the authors and do not necessarily reflect the views of ICTD, nor the UK or Norwegian governments' official policies.

Readers are encouraged to quote and reproduce material from the series. In return, ICTD requests due acknowledgment and quotes to be referenced as above.

(c) ICTD 2013 